\title{
EMPAT PRINSIP KOMPOSISI MENCIPTAKAN DESAIN INDAH, SATU TRIK PEMIKAT HATI PEMIRSA: RHYTHM, DEPTH, BALANCE, UNITY - EMPHASIS
}

\author{
Julianto \\ Jurusan Desain Komunikasi Visual, School of Design, BINUS University \\ Jln. K.H. Syahdan No. 9, Palmerah, Jakarta Barat 11480 \\ julianto@binus.edu
}

\begin{abstract}
Rhytm, depth, balance, unity are 4 main visual composition principles which are abbreviated and simple. The design principles made it easier to design beautiful visual communication but still reflecting strong effects for audience in extracting one trick of desain principles: emphasis. The article adapts literature study method from 7 popular books about visual design communication, along with information beneath each book. The analysis consists of descripted important parts in design principles, then summarize them into 4 (rhythm, depth, balance, unity) plus 1 (emphasis). The article hopefully could facilitate lecturers and students in learning process in DKV classes.
\end{abstract}

Keywords: design principles, rhythm, depth, balance, unity, emphasis, learning DKV

\begin{abstract}
ABSTRAK
Rhythm, depth, balance, unity adalah 4 prinsip komposisi visual utama ringkas dan sederhana. Keempat prinsip tersebut memudahkan cara mendesain komunikasi visual yang indah namun tetap memerikan dampak yang kuat pada pemirsa dengan mengimbuhkan satu trik prinsip desain saja yaitu emphasis. Artikel ini mengadaptasi metode studi literatur 7 buku popular desain komunikasi visual dengan informasi (isi) setara. Analisis menguraikan bagian-bagian pokok prinsip desain, kemudian merangkumnya menjadi 4 (rhythm, depth, balance, unity) ditambah 1 (emphasis). Artikel ini diharapkan bisa memberikan kemudahan dan kesederhanaan dalam proses pembelajaran di kelas-kelas dkv bagi para dosen dan mahasiswa.
\end{abstract}

Kata kunci: prinsip desain, rhythm, depth, balance, unity, emphasis, learning DKV 


\section{PENDAHULUAN}

\section{Catatan dan Corat-Coret}

Berangkat dari masukan berbagai literatur yang dibaca di ranah yang sama kemudian menjadi akumulasi pengetahuan sekaligus memusingkan bagi penulis sendiri untuk menyajikannya kembali kepada mahasiswa, juga lamanya mengajar di matakuliah yang sama memaksa penulis mengupayakan sesuatu (karena belum membuat buku, dan menjadi malu) untuk memberikan yang terbaik bagi pembelajaran di kelas untuk mahasiswa.

Idenya adalah menyimpulkan dan menyederhanakan dari materi kuliah DKV 2 yang mengusung layout (komposisi visual), yang berasal dari berbagai sumber literatur (buku referensi). Selama ini selalu menjadi keluhan dari sebagian besar dosen terhadap mahasiswa yang sebagian acap kali tidak mampu mendefinisikan dan menjabarkan teori-teori yang sudah berulang di sampaikan di kelas, baik sepanjang semester berlangsung, maupun setelah selesai dan lewat semester berukutnya. Dasarnya tentu ingin mempermudah penyerapan proses belajar-mengajar di kelas, khususnya seputar permasalahan hakiki dari desain yaitu mengkomposisikan elemen visual, agar mahasiswa lebih fasih dalam mengingat dan menerapkan prinsik-prinsip komposisi.

Ini hanyalah gagasan individu penulis, melempar wacana dengan tujuan memaksimalkan penyerapan materi kuliah agar terjadi dialog lebih intensif di kelas. Tujuan utamanya adalah memberikan kemudahan dalam pemahaman kepada mahasiswa dalam proses belajar-mengajar pada mata kuliah DKV 2 (kosentrasi pada layout - form) yang pada praktiknya bisa saja menyentuh di banyak mata kuliah sepanjang lingkup desain komunikasi visual, sebelum buku pegangan DKV BINUS terbit. Pekerjaan rumah lama ini memang harus segera dimulai agar terjadi getok tular di mata kuliah lain dalam forum diskusi yang berbeda supaya mendapat format khas DKV BINUS.

Dalam suatu institusi pendidikan manapun yang berhasil di dunia, selalu memiliki identitas sendiri baik itu dari visi-misi, positioning, pengelolaan menejerial, yang berujung pada aset itelektual yang memiliki kekhasan sekaligus menjadi kekuatan yang dibanggakan. Sebagai dosen sangat dihargai memiliki reputasi dalam pendidikan formal maupun karya cemerlang di dunia praktisi pada kompetensinya. Senang jika prestasi itu dibagikan dalam bentuk gagasan pribadi khusus ditujukan bagi pembelajaran di kelas dalam proses transformasi pengetahuan. Kebetulan penulis mengajar di DKV BINUS yang dalam usianya yang masuk tahun ke 12, sudah beranjak remaja jika diukur dalam umur biologis manusia, tetapi prestasi di usia muda tersebut adalah hasil kerja bareng semua komponen yang terlibat dalam proses pembelajaran. Dosen-dosen yang muda dan dinamis, berasal dari berbagai asal institusi pendidikan dalam dan luar negeri yang terkenal, memiliki latar belakang pengalaman cemerlang di dunia praktisi berbeda, aktif di organisasi profesi yang sebagian besar para aktifisnya mengajar di DKV BINUS. Keberagaman dan keterpusatan (melting pot) ini adalah kekayaan yang tidak dimiliki institusi sejenis lain. Aset besar ini perlu segera dikelola dan difasilitasi demi maksud tersebut di atas.

Seorang dosen tidak hanya mereferensikan bacaan yang harus dipelajari tetapi juga memberikan resume kemudian memperbandingkan dari beberapa buku yang dianggap baik dilanjutkan mencari titik temu dari keberagaman itu untuk mendapatkan kemudahan dalam mempraktekannya, karena program S1 masih dalam tarap menerapkan teori (membuktikan teori tersebut benar bisa menuntun dalam upaya penciptaan). Hal ini sangalah mendesak karena sumber informasi yang amat begitu membludak dan mudah diakses tanpa kontrol apakah memang berasal dari sumber yang bisa dipercaya atau tidak. 


\section{METODE}

Dengan penelitian amat sederhana, setelah membaca referensi dengan konten setara, tujuh buah buku terbitan lama dan baru berbahasa Inggris dan satu berbahasa Indonesia, kemudian menterjemahkannya dengan kontektual dalam bahasa Indonesia, mengutip hanya hal-hal pokok berkaitan dengan prinsip komposisi / prinsip desain (struktur), tidak membahasnya secara detail, hanya definisi dan fungsi saja, kemudian mencari persamaan dari banyak istilah yang ada, merangkumnya menjadi ringkas $(4+1)$ Empat Prinsip plus Satu Trik (Rhythm, depth, Balance, Unity + EMPHASIS), dengan menggunakan bagan (silang temu) arahan visual yang memudahkan dalam merujuk berbagai istilah komposisi visual. Memberikan contoh visual hanya untuk bahasan terkait.

\section{PEMBAHASAN}

Tujuan penulisan artikel ini hanya memetakan apa yang tertera dalam buku masing-masing dengan tidak mengubah makna. Diawali dengan memaparkan bagian pokok dari tiap-tiap prinsip desain dan menyatakan definisi dan fungsinya, kemudian memetakannya menjadi empat prinsip, yaitu rhythm, depth, balance dan unity plus satu trik, yaitu emphasis (focal point \& hierarchy).

Pendapat pertama yakni dari Lauer \& Pentax (1994) yang mengusung lima prinsip pokok yaitu unity, emphasis and focal point, scale/proportion, dan balance. Unity memiliki hasil akhir berupa harmony visual unity. Di dalamnya terselip dua pokok, yaitu: (1) Gestalt (proximity, repetition, continuation, continuity), dipakai untuk mendapatkan unity (kesatuan); (2) unity and variety, memaksudkan keberagaman dalam kesatuan yang terkontrol, memuat the grid, varied repetition, emphasis on unity, emphasis on variety, chaos and control.

Kemudian, emphasis and focal point yaitu gagasan yang bagus menekankan emphasis dalam sebuah desain atau komposisi agar memiliki focal point sehingga mampu menarik perhatian dan menghentikan pandangan pemirsa untuk lebih memperhatikan dan akhirnya bisa mengerti maksud dari komunikasi/pesan yang disampaikan. Scale/proportion mengandung makna ukuran dengan perbandingan yang akan menghasilkan kedalaman/depth dan irama/rhythm, sangat berguna untuk sebuah desain komunikasi visual guna menambah persuasi visual dan kedalaman maksud. Balance merupakan control yang paling ampuh untuk mengavaluasi tatanan desain agar terjaga keseimbangannya, walaupun tidak musti simetris.Yang terakhir adalah rhythm, dengan terjemahan irama ini merupakan kedinamisan desain, dengan mengupayakan berbagai cara penyusunan atau layout. Prinsip ini kerap membuat pelihat terperangah dengan kedinamisannya dan menjadi kegemaran desainer melakukan pekerjaan dengan memaksimalkan prinsip ini.

Kemudian, Peterson (1996) memuat tahapan yang bagus, mengarahkan dan menuntun, menawarkan gagasan yang ringan, mencantumkan kolom dan boks 'Bagaimana Cara' dan evaluasi hasil. Balance, contrast, unity, value, dan color adalah lima prinsip yang menuntun untuk memperoleh desain kreatif.

Peterson (1996) memulainya dengan balance, karena beliau beranggapan dalam suatu bidang atau ruang yang terpenting adalah penguasaan ruang dengan mengontrol balance/ keseimbangan melalui teknik memposisikan elemen desain agar desain tetap estetis namun seimbang. Contrast, mampu memperkuat gagasan atau ide, sebab prinsip ini memberikan penonjolan atau tekanan pada desain, dengan contrast perhatian pemirsa dipaksa mengarah ke desain tersebut. Unity, adalah satu kesatuan desain, bisa dicapai dengan beragam cara, kalau menurut buku ini dengan menggunakan grid, adalah satu yang paling mudah, karena keteraturannya, walaupun dengan beragam elemen. 
Value, pada dasarnya value atau nilai kedalaman ini sangat tergantung pada pemilihan dan pengolahan elemen, kehadiranya akan terasa dengan mempertunjukan perspektif, nada, dan gambar yang naturalispun dapat membangunnya. Color, sangat mutlak dan sangat mempengaruhi mood, nuansa, serta suasana desain. Kelompok-kelompok warna tertentu bisa mewakilkan sasaran dan tujuan desain. Bisa hadir sebagai hitam putih atau warna penuh yang dirujuk ke arah gelap dan terang.

Landa (2006), dengan bukunya Graphic Design Solutions, hanya mengadopsi empat prinsip desain yang memudahkan dalam komposisi visual atau layout. Sepaham dengan Peterson (1996), Landa (2006) pun menempatkan balance di urutan pertama, diikuti emphasis, rhythm, dan unity. Balance urutan pertama, sebab menurutnya keseimbangan adalah hal penting menjaga desain menjadi utuh dan harmoni. Emphasis, tentunya juga menjadi konsentrasi utamanya, contoh-contoh desain dalam buku ini tak lepas dari prinsip yang menekankan focal point, termasuk tentunya desain Landa sendiri sebagai pengusung utama prinsip yang memikat perhatian pemirsa ini.

Rhythm, sama seperti rekan-rekan desainer lain, prinsip pergerakan dinamis ini adalah hal yang memberikan identitas kekuatan pada desain, karena dari sinilah hakikat ketrampilan dan kepekaan seorang desainer, jeli dalam memposisikan, mengarahkan, menentukan ukuran, jarak, proporsi, sehingga tercipta desain yang dinamis-estetis. Unity, pastinya ini menjadi control professional, sebab desain yang baik adalah desain yang memiliki kesatuan yang terkendali dan tidak terjadi berantakan atau chaos, sehingga pesan tetap terjaga kosistensinya. Gambar 1 menampilkan desain yang memenuhi kriteria prinsip desain dalam Landa (2006).

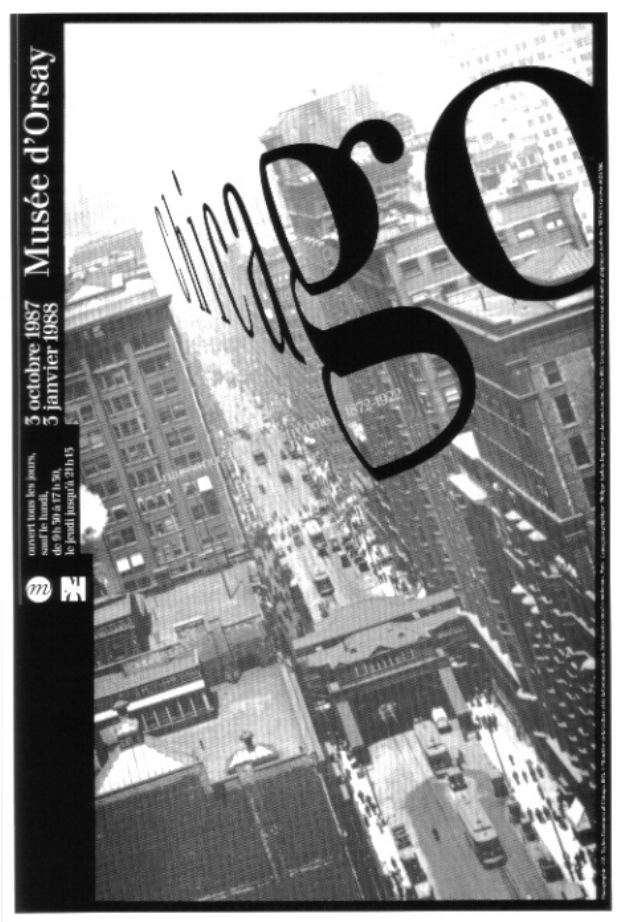

Gambar 1 Desain yang memenuhi kriteria prinsip desain oleh Landa (2006)

Stewart (2006), dengan buku berjudul menarik: Launching the Imagination, memberi makna penasaran pada pembacanya. Buku ini juga menawarkan sesuatu yang relatif baru dan menarik, sebab jika cuma dalam imajinasi tidak mungkin bisa direalisasikan jika tidak di-launching. Sementara, untuk launching perlu kemasan yang direncanakan dan didesain agar orang lain mengerti dan memahami gagasan (imagination) itu. 
Seperti yang ditawarkan Lauer \& Pentax (1994), unity and variety juga dimunculkan oleh Stewart (2006); bahkan dimunculkan di urutan pertama pada bab Principles of Two Dimentional Design. Pada bagian ini, teori Gestalt dan aplikasinya pada patern dan grid menjadi konsentrasinya. Keberagaman elemen harus dikemas apik agar muncul sebagai satu kesatuan, begitulah kerja prinsip ini.

Sama seperti tiga pengarang sebelumnya (Lauer \& Pentax, 1994; Peterson, 1996; dan Landa, 2006), balance adalah bagian penting dalam kontrol ruang. Sementara itu, dalam konsep scale and proporton pun masih sepaham dengan Laurer \& Pentax (1994). Emphasis, prinsip ini juga telah diterangkan pada Landa (2006).

Prinsip lainnya adalah creating the illusion of space, penulisnya ingin mengungkapkan adanya ilusi ruang alias kedalaman pada desain, sehingga melahirkan suatu nilai (value). Seperti yang dituliskan Peterson (1996): “...using design basics to get creative results.” Prinsip selanjutnya, yaitu dinamic space, jika diterjemahkan menjadi ruang yang dinamis, dengan demikian perlu adanya pengaturan dan penataan yang dinamis, itu hanya mungkin jika menggunakan prisip komposisi rhythm untuk membangunnya.

Prinsip the illusion of movement merupakan pergerakan yang tak nyata namun terasa, kira-kira begitu yang dimaksud, ini adalah hasil komposisi dinamis dan penempatan posisi serta permainan scala sehingga membentuk ruang dan kedalaman dengan adanya pergerakan tersebut. Prinsip determining priorities sangat penting dilakukan, jika tidak akan terjadi saling menonjol atau berkejaran bahkan saling berteriak satu dan lain antara elemen yang ada.

Rustan (2009), dalam bukunya Layout Dasar dan Penerapan, merupakan seorang pengarang buku desain 100\% asli Indonesia; konsistensinya perlu acungan jempol, setia pada waktu, terus menerbitkan buku setiap tahun, minimal satu. Gaya bahasanya lugas cerminan pribadinya, contoh dengan perumpamaan dekat dengan keseharian, tips and triknya ampuh memberikan penjelasan praktis. Karena beliau dosen dan juga praktisi, maka gagsannyapun sederhana hanya empat prinsip yang dikemukakan yaitu: (1) sequence, adalah urutan, banyak juga yang menyebutnya hirarkhi atau aliran, begitu beliau memaparkan dengan sinonim kata yang lengkap; (2) emphasis, penekanan atau focal point atau point-of-interest, selalu dengan persamaan kata, memudahkan orang untuk mengerti. Stewart (2006), Lauer \& Pentax (1994) pun menekankan prinsip ini untuk mendapatkan perhatian pemirsa; (3) balance, keseimbangan, pembagian berat yang merata pada suatu bidang layout, bukan berarti seluruh bidang dipenuhi dengan elemen desain, tetapi lebih pada menghasilkan kesan seimbang dengan menggunakan elemen-elemen yang dibutuhkan dan meletakannya pada tempat yang tepat. Tidak hanya pengaturan letak tetapi juga ukuran, arah, warna dan atribut-atribut lain; (4) unity, menciptakan kesatuan secara keseluruhan. Sebagaimana layaknya kita memakai pakaian: celana, atau rok dipadukan dengan baju, blazer, sepatu dan ikat pinggang, satu sama lainnya harus dipadu padankan, demikian perumpaan khas penulis buku ini yang dekat dengan pemirsanya. Dua prinsip terakhir ini memang wajib hukumnya bagi yang melebelkan dirinya desainer untuk mengontrol desainnya.

Ambrose \& Harris (2007), dalam buku The Layout Book, sangat member inspirasi dalam katagori, karena mereka memisahkan antara The Vocabulary of Layout Design dan Articulation of Design. Pada The Vocabulary of Layout Design dan Articulation, memuat: Gestalt, proximity, unity, alignment, contrast. Untuk tiga prinsip Gestalt, unity, contrast, sudah dibahas di atas. Sementara itu, proximity, mengartikan kedekatan sebenarnya ini termasuk muatannya teory Gestalt, kedekatan yang dimaksud menyatakan jarak antara elemen desain yang mengadakan pengelompokan, menyatu, menjadi satu kesatuan, misalnya hubungan caption dengan gambar. Alignment yaitu kebutuhan menyusun sebuah desain agar memudahkan pemirsa dalam mengintrepretasikan informasi di seputar desain, mengartikan penyusunan yang dinamis mengarahkan susunan. 
Namun pada Design dan Articulation of Design diuraikan menjadi: hierarchy, balance, juxtaposition, consistency or repetition, white space, rhetoric. Hierarchy dan balance, sudah dibahas terdahulu, sementara itu juxtaposition adalah menempatkan elemen desain di lokasi yang mengambil perhatian atau dengan cara yang tidak biasa, menjadi point-of-view dengan suatu penekanan pada pemirsa. Consistency or repetition mengharapkan kesinambungan, hubungan satu dan lain elemen yang mungkin ada diberbagai media terpisah, yang diciptakan oleh unity (kesatuan). White Space, adalah ruang putih, kosong, bermain dengan elemen minimal, member tekanan (emphasis) pada pemirsa. Sementara itu, rhetoric yaitu bersifat persuasif, hal yang fundamental dari desain, belum menjadi desain jika tidak memenuhi sesuatu yang baru dan persuasive, kedalaman / depth totaldari sebuah desain yang menghasilkan hal ini.

Lupton \& Phillips (2008) mengadaptasi teory lama namun dkemas dengan indah mengikuti perkembangan teknologi yang dituntut zaman. Mengusung prinsip-prinsip yang menarik untuk didiskusikan, yaitu: (1) rhythm and balance, sudah diulas dimuka namun dalam buku ini mereka menggabungkannya agar kedua prinsip ini terus terjaga kerjasamanya; (2) scale, juga sudah dibahas dalam Lauer \& Pentax (1994); (3) texture, adalah keadaan elemen yang memberikan kesan berpermukaan, hingga tercipta dimensi ruang (depth); (4) color, sama dengan tekstur berfungsi menciptakan ruang dan kedalaman (depth), karena tujuannya untuk menciptakan mood; (5) figure and ground, permainan positif negatif inibermaksud untuk mendapatkan kontras, sedangkan kontras bisa dipakai sebagai focal point,dan focal point itu sendiri adalah emphasis; (6) framing, diharapkan ada suatu kedalaman (depth) dalam desain; (7) hierarchy, sudah dijelaskan prinsipnya relatif sama (8) layer dan transparancy, tentunya sangat menginspirasi pada ruang yang merujuk pada kedalaman (depth); (9) modularity, grid, pattern memaksudkan suatu sistem, keselarasan, dan kesatuan (unity); (10) diagram, bertujuan memberikan keterangan yang lebih menjelaskan secara visual secara berurut, mana yang harus didahulukan dan kemudian, prinsip hierarki adalah yang pas untuk mengadopsinya; (11) time and motion, pergerakan dan waktu memberi inspirasi yang membutuhkan penghayatan, pada orang menggambar saja sudah membuktikan gerak dan waktu, apalagi kamera yang digunakan untuk mendpatkan gambar, kreativitas dan kedinamisan desainer dalam mengoptimalkan penggunaannya akan memberi hasil maksimal, begitu pengarangnya menjelaskan. Jadi jelaslah apa yang dimaksud yaitu rhythm and depth.

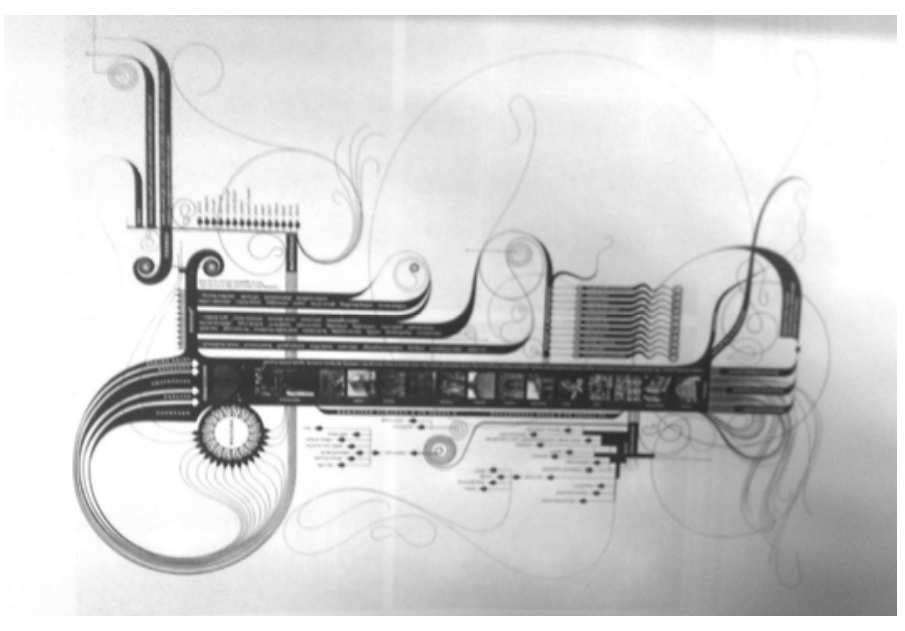

Gambar 2 Diagram yang menyatakan hierarki, karena tuntutannya menjelaskan urutan kepentingan 


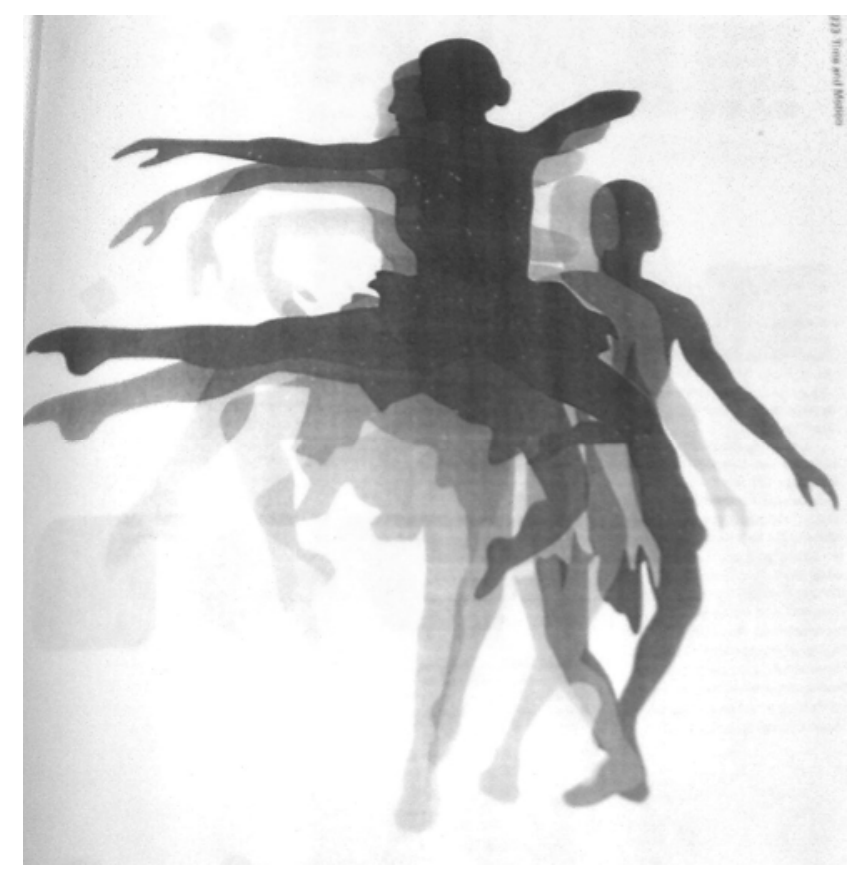

Gambar 3 Layer dan transparency, visual yang bertumpuk memberi kesan ruang sehingga terjadi kedalaman (depth)

Konsep 4+1 prinsip desain ini sudah dilakukan oleh beberapa mahasiswa DKV BINUS University. Di antaranya terdapat pada Gambar $4-9$.

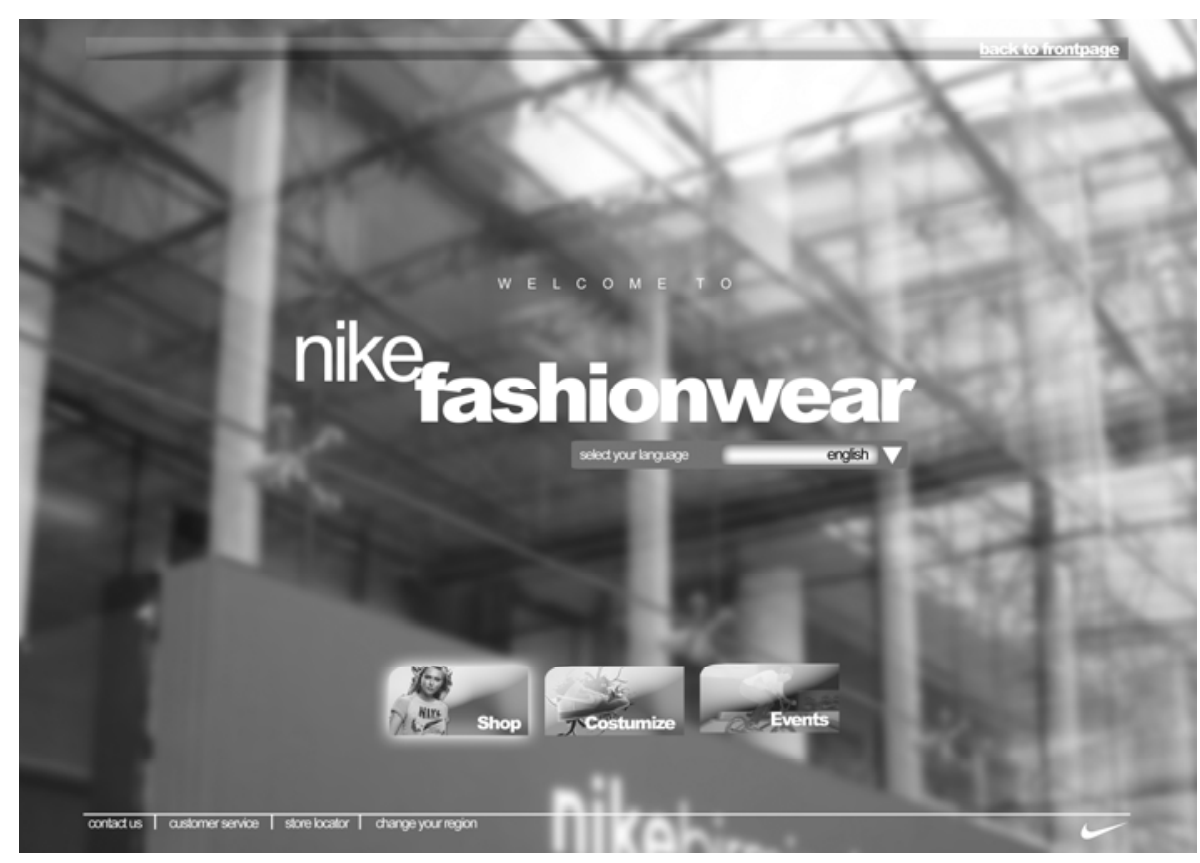

Gambar 4 Karya Rekhaza Panji - desain website,

kedalaman (depth) yang sangat kuat, memunculkan emphasis yang kuat pula 


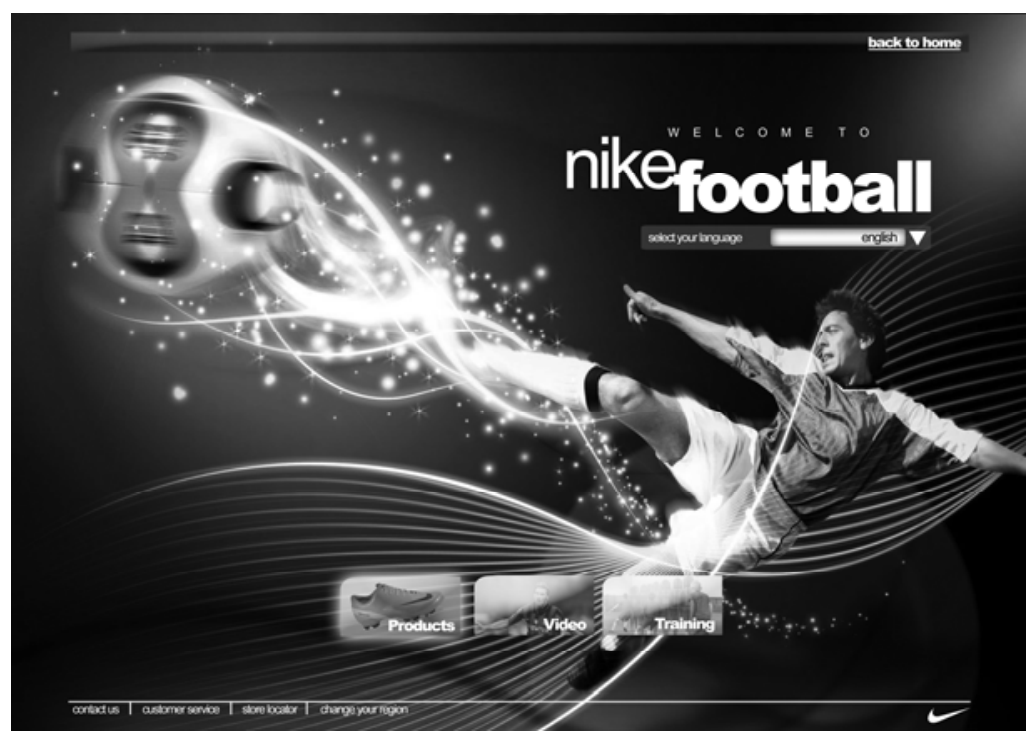

Gambar 5 Karya Rekhasa Panji, desain Website, memunculkan rhythm yang dinamis, menjaga unity baik dalam satu frame maupun keduanya

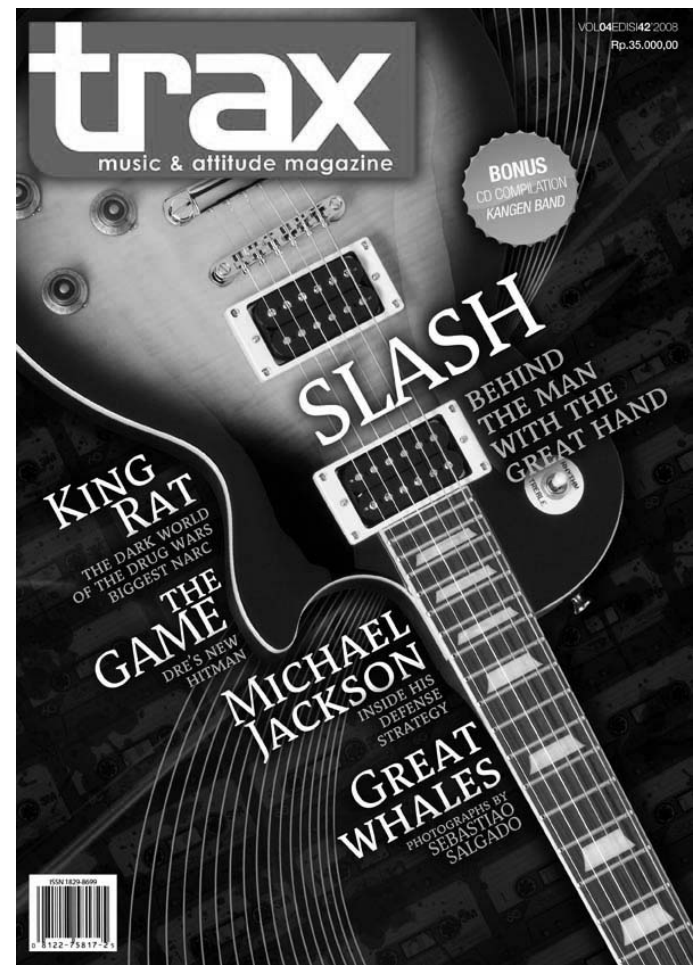

Gambar 6 Karya Harry Muksit, desain cover majalah musik, kekuatan gambar yang menyatu dengan komposisi huruf, memberi kesan menyatu-utuh (unity) dan menjadi penekanan (emphasis) untuk desain ini dan kedalamanya (depth) pun tercipta 


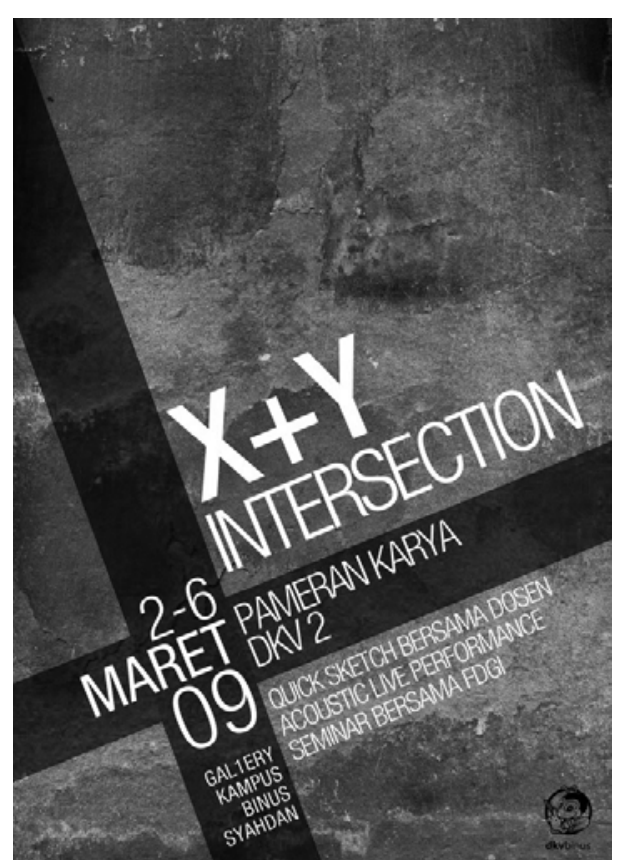

Gambar 7 Karya bersama tim DKV 2 BINUS, Poster pameran kelas DKV2,

emphasis yang kuat, walau tetap menjaga unity dan balance background bertekstur menghasilkan depth yang cantik

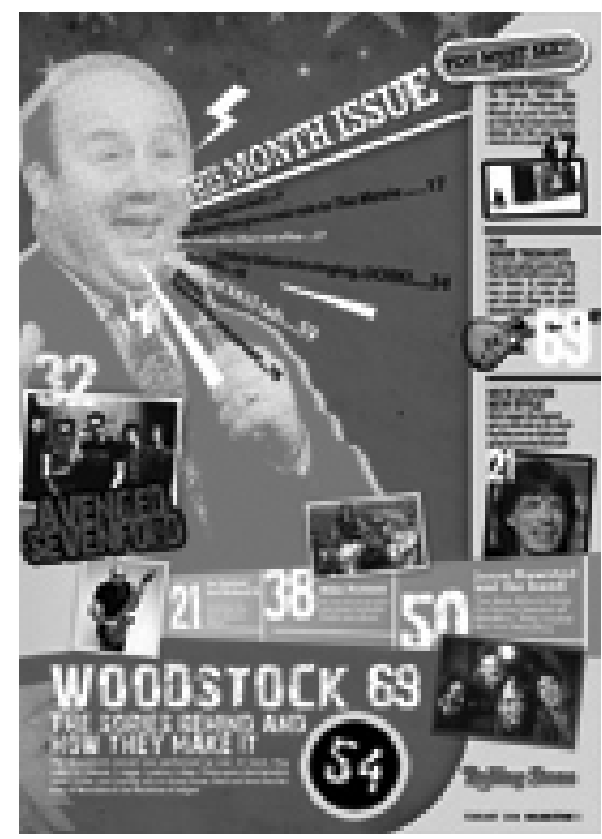

Gambar 8 Karya Rico Waas, cantik dan berhasil sekali menampilkan rhythm, dinamis namun tetap menjaga unity pada elemen bidang, warna dan arah; emphasis di layout dan warna 


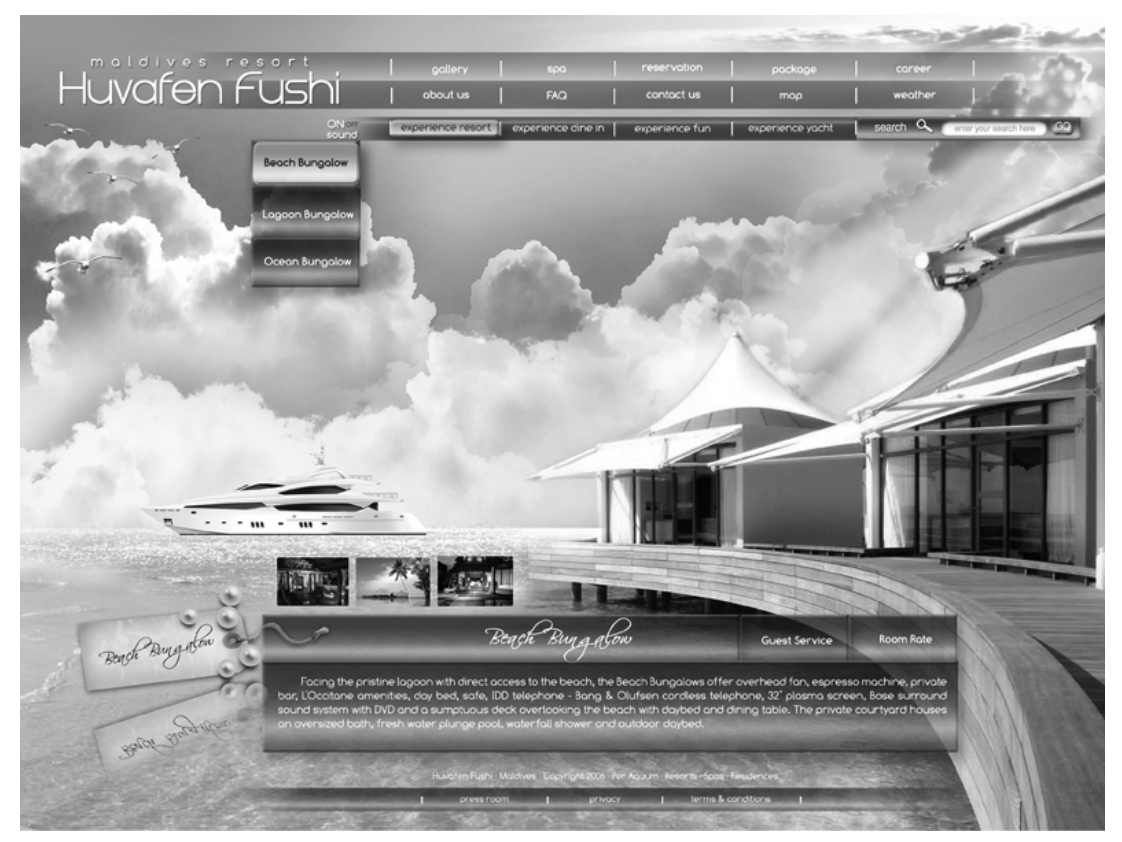

Gambar 9 Karya Fiona Frany, menampilkan kedalaman (depth) yang apik dengan menggunakan perspektif dan layering, kesan clean tetap terjaga unity-nya, hierarki visualnya jelas untuk navigasi.

\section{PENUTUP}

7 (tujuh) buku bukan pembatasan sumber pembahasan. Menarik beragam pendapat dan gagasan yang memberi kekayaan dan khasanah perbendaharaan kata dan pendekatan yang kesemuanya memuat spesifikasi khusus dan tujuan tertentu dari masing-masing pengarangnya dengan istilah yang ditawarkan. Sudut pandang yang kreatif memberi inspirasi luas dan kaya imajinasi. Namun dari keberagaman itu sebagian besar istilah bisa dirujuk menjadi tujuan yang relatif sama. Sehingga penulis dengan kerendahan hati bermaksud meringkas menjadi Empat Prinsip Utama: rhythm/irama, depth/kedalaman, balance/keseimbangan, unity/kesatuan, dan satu trik dahsyat emphasis/penekanan. Banyaknya referensi atau buku yang disajikan untuk dibaca dan didiskusikan sangatlah penting, karena itu menjadi keluasan wawasan dan pengetahuan dosen sebagai pengajar, tetapi tidaklah bijaksana jika begitu saja diberikan atau dilempar ke mahasiswa untuk dibaca sebagai sebagai referensi, hendaknya ada pembahasan yang dibagun dengan diskusi dan Tanya jawab, agar membuahkan pemahaman yang lebih mendalam dan komprehensif, yang akhirnya selain mampu memahami prinsip dan menerapkannya sejatinya dengan tangkas dapat memberikan penjelasan sebagai wahana konsepsi praktis. Pada akhirnya mahasiswa dengan mudah dan pasti serta penuh kenyakinan dalam menerapkan segala teori yang sudah mereka terima. Sangat berharap segera, masing-masing dosen pengajar di matakuliahnya melakukan hal yang dianggap perlu untuk didiskusikandalam koordinasi matakuliah masing-masing, dengan demikian munculah satu per satu hal baru yang kelak menjadi format sekaligus kekhasan perguruan tinggi tertentu. Simpulan ini terangkum dalam sebuah Gambar 10. 


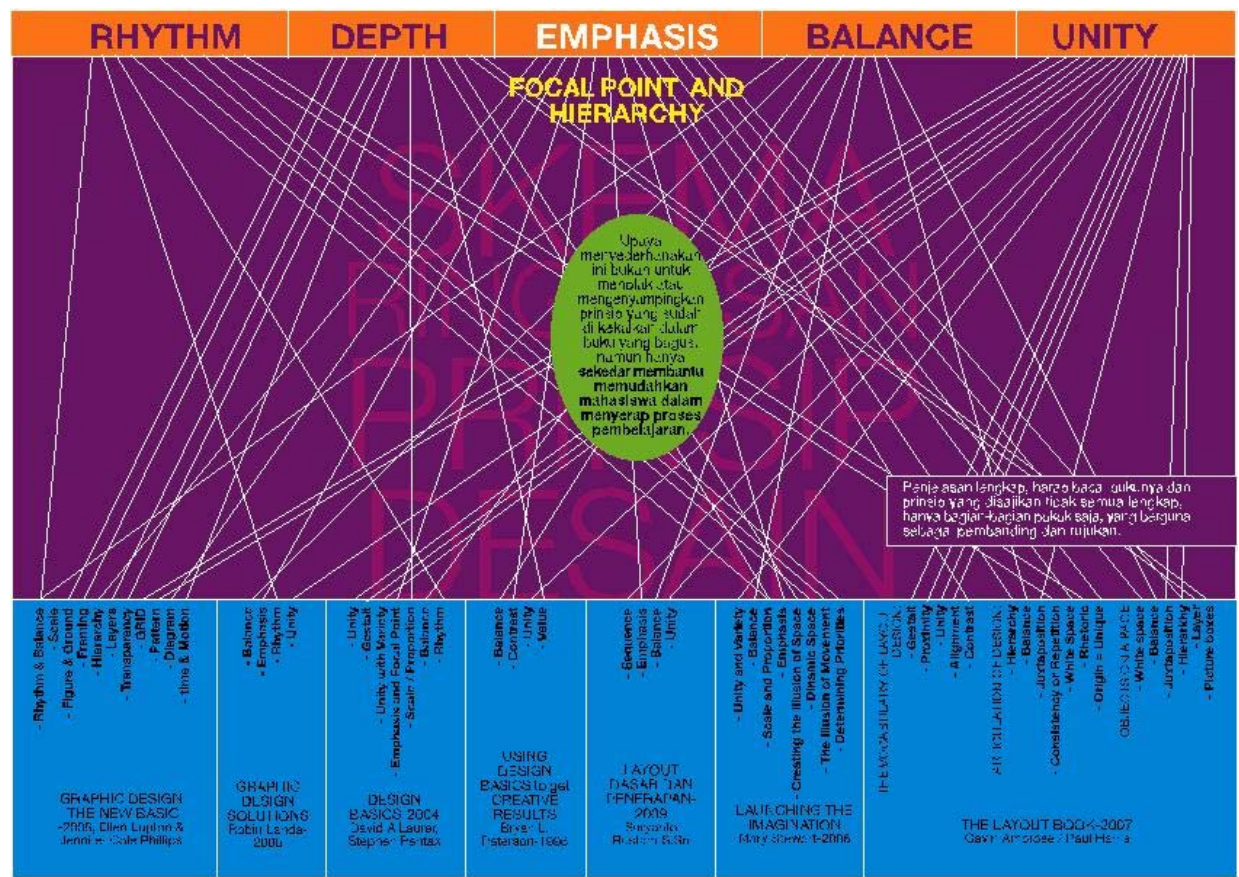

Gambar 10 Diagram rujukan ke 7 (tujuh) buah buku menjadi empat prinsip (Rhythm, Depth, Balance, Unity) plus satu trik (Emphasis)

\section{DAFTAR PUSTAKA}

Ambrose, G., \& Harris, P. (2007). The layout book. Switzeland: AVA Academia.

Lupton, E., \& Phillips, J. C. (2008). Graphic design the new basic. New York: Princeton Architectural Press.

Landa, R. (2006). Graphic design solutions. New York: Thomson Delmar Learning.

Lauer, D. A., \& Pentax, S. (1994). Design basic. The Ohio State University: Wadsworth/Thomson Learning.

Peterson, B. L. (1996). Using design basics to get creative results. Cincinati, Ohio: North Light.

Rustan, S. (2009). Layout dasar dan penerapan. Jakarta: Gramedia Pustaka Utama.

Stewart, M. (2006). Launching the imagination. New York: McGraw-Hill. 